\title{
LEARNING LIFE BALANCE: A STUDY TO REGAIN MENTAL PEACE AND MENTAL HEALTH OF SENIOR HIGH STUDENTS
}

\author{
R. Madhakomala ${ }^{1}$, Johansyah Anwar ${ }^{2}$. \\ State University of Jakarta \\ r.madhakomala@unj.ac.id \\ johansyahanwar@gmail.com
}

\begin{abstract}
The aim of this study is to observe the level of happiness enmjoyed among senio high students related to current school practices and national learning system regulated by the authorities.The world of learning has changed when school grading has been becoming as one of the most obligating and influencing source of educational success in within the institution. The historical myth of study with fun and enjoyment has gradually but sure moved to the sense of study hard for the sake of the future by consuming most of the daytime hours. Nevertheless, this is when the problem of lack of students' quality time commences. Students do not realize that they are moving to the unsatisfied part of the learning life, as so many times they are also intrigued with and by computers; when unconsiously they lose the lovely ones and the world outside.This study attempts to show how senior high students can achieve the so-called learning life balance to regain their mental peace by more contacts and relationships with families, the environment, and the world around. This is how the world of educating has to recognize and understand the value of happiness of a senior high student. This is how the regulator has to manage the system to flow to the building and the establishment of the well-being of nowadays students.
\end{abstract}

Keywords: Mental Health, Mental Peace, and Learning Life Balance.

As student, sons or daughters would bring their parents to be most graceful when the term of reporting ends up showing as the number one ranking in the class of a well-known school. Being satisfied and proud, they may exposingly chat among guardians of how their kids have been working so keen and hard, spending all day long with books and computers under the supervision of related teachers. Is this the only goal of the parents?

Teachers may join the happiness of those parents by accepting congrate shake-hands with smiling faces by the parents. On the other side of the coin, they may also involve in the pride as members of the famous high-graded school in the town. Do they realize how well they have been running the mission of education for all those students?

Students may smile even giggling among them, however internally contemplated under certain unpredicted circumstances. Yes, they are emotionally 
happy looking to the one week no-class ahead. They have been spending all full busy days with the class, external obligated school activities so many times on Sunday, additional home study (directed by parents), and facing computers to finish homeworks. They are beaten to pursue the best in the extra-class led by the school. They have been doing well so far. Nevertheless, how is the value of their happiness? How did they love their full busy days? Indeed they are stumbling on happiness, which is certainly desirable to balance their full busy days.

They have no love; they did study, they did finish their homeworks, they joined the extra class, they followed their parents to enrich their knowledge (as said so); all due to obligations. Obligations by the school teachers and obligation by their parents. They are exploited for the sake of the school and for the sake of the parents' pride. They are beating their brains' out to attain these exploitations. They are mentally tired and very exhausted. They are under pressure, which if it goes further, may gone to something very destructive. School fighting and even narcotics may be among those the most unmeaningful. Both the schools and parents are gradually taking out their liberty to learn from the environment and to understand the world, which play such a significant role in the development of childhood life.

They are presently happy because they feel the liberty in the upcoming week. And this is the moment they love much; whiile actually, love being a student comprises of loving the class, loving the school or institute, loving the community, and loving the nation; despite of loving to be at home. The fully busy weekdays provide neither balancing for all those students to look at the environment nor to funny chat with other family members at home, not to even play with neighbours. Unintentionally, they feel the need to counsel with parents, taking into account the so-called appreciation, recognition, and feedback; they feel the need to link with environment and neighbourhood to generate attraction, adaptation, and care. Nevertheless, time and space are so limited.

All these things occur because we work for goals. The school has its own goal to avoid degradation, the teachers have their own goals as members of a famous high-graded school, and the parents pay special concern with class ranking. Students seems to be the objects, while actually they are the subjects for their future. They have mark two important areas in the life of student: study and real life. Thus, learning life balance connected between school with its spaces of study and non-class matters in the societies and families. Provide them with ample time to link up in the non-class matters. Lets students set up and attain their well-being by themselves as the subject to drive their intelligence. If they do get top marks then great. But if they don't, then don't take away their growing self-confidence from them. Keep telling them that it is just a grading in school. They have been cut out from so much bigger things in their lifetime. 


\section{Mental Peace and Mental Health}

Mental peace and mental health of students, especially in the senior high grade, as it is recognized that many of the transition points in life can be particularly challenging. Although there have been significant developments in approaches to teaching and supporting students with factors that can contribute to their well-being as member of the surrounding community, it is obvious that students nowadays are under pressure to spend almost all their time for the sake of good grades in school.

The positive sense of mental well-being, which covers mental peace and mental health, encompasses the emotional resilience that enables students to enjoy life, to survive pain and disappointment, and to be more engage in productivity which in overall, contribute more to the society or to the community. It is a consideration of physial, social, and spiritual well-being. Students may have different needs and vary in their experience of mental peace and mental health. The underlying causes vary from one student to another, and certainly not all directly related to their higher education at school.

Transition points in their life can be challenging and likely adapting to significant changes in lifestyles and cultures in their surroundings, among others:

1. Some may not be staying together with their parent-by-blood. They may be following their closed relatives or living alone by rent.

2. Some may be new-comers, moving from another area which may have different ways and/or habit of living.

3. Some may come from different cultures. Cross cultures may be difficult withour thorough understanding among people.

4. Some may not communicate well in familiar language; and

5. Some may need to adjust to the local pattern of life and habit.

All those changes are viewed as recognizing levels of stress; Nevertheless, if carefully managed and allowing proper adaptation among the stay-home family and community, some levels of stress does not necessarily have to have a negative impact and can be stimulating. This is the reason why teachers at school need to pay keen attention to allow students to properly adapt themselves in their stayhome family, their surrounding community, and the developing world.

\section{Intuitive Thinking}

Students may know that the word happiness means and may memorize the definition of happiness, but they do not learn how to apply happiness in a wide variety of situations and conditions; they may know the word effcient, but may not be able to describe whether they are behaving really in an effcient manner in the real world. They seems to be lacked of the power of mind to do, to act, or to react quick, readily insight, and simultaneous - on a certain phenomenon. Unfortunately 
much of what originally given and learned in school was mostly abstract and unconnected to everyday life, experience, and circumstance.

This is so natural for school teachers to teach as one was taught, then students are probably doing exactly what those teachers did, learning in as abstract way to perform for grades, and no to gain knowledge, skill, and insight by transforming their behavior in thr real world.

This is the reason why so many learning process in high school is not transfered and balanced to the real world of experience. It lacks the intuitive basis and the insight for the transfering and balancing. And this is the reason that those students, deep in their insight feelings, raise their hands to enter into the real world: the family and the environment. This is the world of dreaming, doing, acting out their lives, facing obstacles and problems, every step by step to struggle for the searching of happiness and meaning.

There would be a student who may say, "I don't need to think. I just do things what I think I need to do". There would be another student who may say," I keep on thinking from time to time. I believe in what I have thought and what I want to believe. I will confront anyone who asks me to do what I don't want to do". In the middle of both, there would be a student who may say, "I think a lot as it helps me to keep on learning. I want to understand my parents and playmates. I want to understand everybody and everything. I want to make everyting better and better for everyone, not only for me".

Each one of them expressed how they introduce themselves in terms of their attitudes toward thinking, how they work their way of thinking, and what they aim through their thinking. Each of these characters are important.

The first character of "I don't need to think" indicates the student as being so literally and thoughtlessly, just doing what is being told, nor she need to ask. She will make mistake only because she doesn't listen closely and monitor what she hears for accuracy of interpretation.

The second character of "I keep thinking from time to time" indicates her value of thinking; however, she thinks to gain advantage and to get whaat she wants. She put her desire on top of the rights and needs of others. Unlike the first character, she learns the power of figuring things out for herself. She will apppreciate the power especially in groups, taking this advantage to become the leader and to exercise control over the others. She doesn't care at all about others.

In contract to the first and second characters, the third character of "I think a lot as it helps me to keep on learning" discovers herself having a mind and can use her mind to solve problems, to protect herself, and best of all, to get along wih others. She learns that everybody has her own mind, desires and needs, rights, and different ways of looking at things. She learns how to enter into the thinking of others, how to look at people's point of view, and how to protect herself without violating the rights of thers. 
By introducing these characters, it is the best for school teachers to assist students in the understanding of critical thinking through intuitive. Breathe the life of students to build mental bridges between the abstract and the concrete, between the theories and practices. Though there are so many ways either by assumptions or examples, but providing them to understand the world outside school, the family and the environment, would be more than enough to develop the intuitive thinking. Provide them with ample time to understand the relationship and communication of parents, relatives, and the environment. This is the need of balancing their life of learning.

\section{Cognitive Development}

Understanding the world which covers the family and the environment, is the developing process beginning at birth. It develops from time to time; from just looking to touching, from the understanding of symbols to reading letters and numbers, from understanding of cause and effect relationship to demonstration of logic thinking and comparison. Every human being has to understand the regularity and predictability of the planet and the contents of the planet, a knowledge which is known as cognitive development. This is a type of knowledge learned totally through mental processes and sensory perceptions. It is a case of relationships and interactions utilizing the five sensory modes - seeing. hearing, touching, tasting, and smelling.

As it related to mental processes and sensory perceptions, approach by every student would be from unsimilar perspectives emphasizing on different aspects. The theories of Jean Piaget and Lev Vygotsky have probably been the most influencing on our discussion of how young children learn.

Piaget focused on the way individual acts upon objects in the environment in order to build mental models of the way the world works. Vygotsky looked more closely at the way children acquire knowledge through interaction with more experienced people and at the role language plays in the process.

For Piaget, the physical environment is important and the adult role is to make sure that environment is rich and stimulating. While for Vygotsky, the social environment is important and the adult role is to help children tackle challenges that are just a little beyond and what they could do alone.

However, both Piaget and Vygotsky have had the similar understanding that environment and the role of adult play significantly in the growing process of young children. Though different in their expression in the interaction with people and tackling challenges, it is just all about how they absorb knowledge by communication for the sake of problem solving.

Knowing that students must construct their own knowledge does mean that educational institutions have to widen the social life of students. Let students join the culture in which they live and let them learn through interaction with anyone in the environment to gain more and more experiences. And it is not a must that 
everytime is a time of success. Fail is just a matter of a delay in attaining success, and this the significant part of the role of adults who are more experienced in the human interactions of a certain culture. On top of all, interaction and communication in such environmental relationships plays as a very sigificant factor in the life of students, despite of their official learning process at school. Unconsciously, it is a demanding factors from their inner side, to adapt to the developing culture outside the school walls.

In his "Piaget's Theory of Cognitive and Affective Development", Barry J.Wadsworth quoted that Piaget's system for conceptualizing intellectual development was greatly influenced by his early training and work as a biologist. Functioning as a biologist, he became vividly aware of and impressed by the interaction of mollusks with their environment. Mollusks, like all living organisms, constantly adapt to changes in environmental conditions. It is therefore, Piaget came to believe that biological acts are adaptation to the pgysical environment and help organize the environment.

Adaptation is giving students every opportunity they may have to discover by themselves. Guidance by adults is not to tell them wrong which will not change their thinking; Instead, provide more and more opportunity. Let them discover their own construction of knowledge, the theory of Russian psychologist says as the social construction of knowledge.

In their book "Cognitive Psychology"; Robert L.Solso, Otto H.Maclin, and M.Kimberly Maclin stipulate that right now, and at any moment, just like the air traffic controller, you are involved in a myriad of cognitive activity. You have external inputs of this information on the page, and your surrounding environment (the quiet of library, or the chaos of the student union or your residence hall); all these inputs affect your selective attention of the text you are reading and ultimately your abilityto accurately perceive this information (page 4). This type of involvement at any time in the family or the environment is unintentionally and unconsciously insisted by most of the students beside their busy days with related school activities.

V.Gregory Payne and Larry D.Isaacs in "Human Motor Development: A Lifespan Approach" that Piagetian theory is an account of human cognitive development (page 206). Piaget said that there are four basic cognitive concepts which have to be grasped: the concepts of schema, assimillation, accomodation, and equilibration. These concepts are used to explain how and why cognitive development occurs. Conceptually, cognitive growth and development proceed through these concepts at all levels of development. From birth through adulthood, knowledge is constructed by every individual. From schemata of childhood to schemata of adulthood, accomodated and assimilated to the result of qualitative change in intellectual structures, prociding them a cumulative coordination and constant construction; whereas the process of the concept of equlibration regulates all those in their internal mechanism. 
The exposing of these cognitive development process reveals that social living plays a very significant role in the developing growth of human being, from birth to adulthood, inculding students who are spending most of their daytime in school. Pushing students to pay their keen and full attention only to day classes, literatures, teachers, and computers will drag them to he unknown development of the world and hold them from the building the cognitive development.

To be tough, to keep standing the test of time, and to develop a constant growth of cognitive development; students have to know the world outside the school walls, and beyond literatures and computers. Balance their related learning process in school with the real social living, from in within the family, the neighborhood, and the global environment.

\section{Motoric Development}

The development of students as part of human development is a diverse, complex area of study in which we cannot consider ourselves completely educated until we understand all aspects of the changes that occur throughout the lifespan. V.Gregory Payne and Larry D.Isaacs in "Human Motor Development: A Lifespan Approach" describe that they deliberately chose to use motor as a general term to refer to any form of human movement behavior, rather than using the more common psychomotor. Both further elaborate that human behavior is not compartmentalized, there is a complete system of constant, reciprocal exchange among an individual's cognitive, affective, motor, and physical aspects (page 48). Reciprocal exchange of the system among students, as a matter of fact, is nothing but a means of socialization outside the schoolwalls which is a lifetime process, facilitating individuals' function within the society, even from their childhood.

Socialization, by Coakley as further quoted by Payne and Isaacs, is a dual process of interaction and development through which human beings learn (1) who they are and how they are connected to the social worlds in which they live, and (2) the orientations used as a basis for the individual behaviors and group life in the same worlds (page 48). This is how the process teaches every members of the society, which is insisted by thise students, every single social role. There are so many social roles in any society. There are occupational roles, family roles, and society roles; in which should be well exemplified and by which would be heavily influencing human motor development. Occupational roles like police roles are illustrated by a police officer by specific expected behavior. Family roles can be illustrated by a mother or a father to exhibit certain behavior which influences the motor development of kids. Society's role expectations by no exception, influences human motor development; nevertheless, take in account that there would be variations of every roles in different cultures.

As Payne and Isaacs stipulates, the family is the most important socializing force in the lives of most children. The family is also the earliest and, in most cases, greatest determinant of a child's movement choices and movement 
success, because it strongly influences the child's attitudes and expectations about movement. (page 55). As movement choices and movement success grow from time to time, attitudes and expectations keep developing approaching the era of adulthood. The era of adulthood comprises of the era of senior high student, the era of working, followed by the era of having spouse to take care of kids.

Among students, sport participation would be one of the significant examples of motoric development, despite of time spent for class-related activities. As a physical activity play, it serves as a mechanism to build strength, endurance, and possibly for the sake of maintaining healthiness. Experiences proved that participation in informal, but more significant in formal sporting activities during high school years may design themselves, among others to (1) increase their level of self esteem, growing as they are able to perform better and better, (2) feel of having physical competence, and (3) increase their personal image among friends and community members. Movements in sports, with or without purpose, would increase the flexibility of muscle actions and increase skill. Muscle actions are meant to be goal directed activities that consisted of motoric body movements. In other words. muscle actions are activities that consist of body movements to a directed goals. Skill is meant to be a motoric skill that requires efficient motoric body movement to achieve its goal; however, to take note to distinguish motoric skill from another types of human skills. As an example, mathematical solving is a skill while it does not need any type of body movement. From day to day, week to week, even year to year, each human being gradually but sure develops his or her psycho-motoric goals, skills, and actions to attain each step by step maturity in life in the environment.

R.Madhakomala stipulates that mahasiswa berbahagia karena merasakan kebebasan belajarnya dan mahasiswa senang karena apa yang dipelajari di kelas sesuai dengan harapan hidup. Hal ini hanya mungkin bila mahasiswa mencapai kedewasaan setelah sekian lama dapat membiasakan diri terlibat di lingkungan kehidupannya. Disinilah mahasiswa perlu memahami konsep pembelajaran kontekstual atau lebih dikenal dengan contextual teaching learning or CTL. Conseptually, she emphazises the engagement of students in their living environment to attain their maturity of life. Madhakomala further cites the three important elements in the implementation of contextual teaching learning: (1) the individual himself, (2) the group involved, and (3) the environment. The involvement of groups and environment, as she further describes, is a significant source of learning processes to create an active, creative, stand alone, and qualified human being with maturiry.

There is no question that all these types of psycho-motoric development could be achieved without blending students in the real social life, the family and the surrounding environments, from and by communication and relationships as friends, sport memberships, and neighbourhoods. Taking special note on the era of senior high student, it is advisable to understand why consuming too much daytime 
for every activities related learning at school needs a very special attention. It is also advisable to understand that they unconsciously feel the need to enter into the society for their motoric development, and eventually for their well-being and happiness.

The contextual teaching learning as cited by Madhakomala acts as mutual learning process by both students and teaches based on: (1) the concept of internal and external sources of the learning process itself and (2) the concept of learning interest and motivation. It is therefore good, to understand how students are putting their interests at school and environment (including their families) and how they motivated to perform at school and in the environment.

\section{METHOD}

As part of the effort to understand how senior high students value their time and well-being at school and in the environment, a simple short but straight to the point survey was conducted among the second grade (grade eight) of two wellgraded senior high school in Jakarta. The survey assumed the understanding those students (82 repondents) as having certain level of recorded intelligence among mostly senior high students in Jakarta to be the respondents in this survey. Survey utilized and implemented qualitative approach under the method of content analysis. Data were collected and observed by interviews, observation, and study on documents as designed by Miles and Heberman.

Survey was conducted among higher educational students due to couples of considerations, as follows:

1. As higher educational students, it is assumed that they have been in within a structured and purposeful environment. They are in the transition from childhood to adulthood, insisting to fabricate the intuitive thinking, cognitive development, and the motoric development to the maturity of the living.

2. The environment is assumed to provide opportunities for academic and personal achievement leading them to a sense of identity and increase self esteem. It may starts by groups, from sporting group to relationships as friends or neighbourhood.

3. The environment is assumed has been offering opportunity to learn to manage multiple demands;

4. The environment is assumed to provide opportunities for creativity, community involvement, and contribution;

5. The environment is assumed to be friendly.

Students were asked how they judge the learning system conducted by the school, how they value their time spend in school, how they feel about the need of being at home, and how appraise their liberty or freedom to decide what they live to and what they want to do. Surprisingly that more than $79 \%$ of respondents say facing difficulties in following the learning system conducted at school, more than $87 \%$ of respondents say that time spent at school has been too long and requiring 
to be back home sooner, more than $69 \%$ of respondents demand to spend time and enjoyment with families and relatives, and more than $53 \%$ of respodents feel that they don't have much freedom to decide what they love and what they want to do. Unintentionally by this survey, they are providing more information to enjoy more positive family time and to avoid the internal classroom competition to attain the ranking, which is mostly only for the sake of their parents' pride.

At the end of the survey, they were given five choices, comprising of:

1. Additional pocket money,

2. Shorten school hours to be back home,

3. Additional three holidays in a month,

4. Terminating the class-ranking program, and

5. Terminating additional home study.

\section{RESULTS}

When it comes to the choices fo what are their passions (picking up 2 out of 5 alternatives), more than two third insisted to shorten school hours to be back homr and more than one third of them insisted the termination of class-ranking program. It is not they reject additional pocket money that they insisted in this survey, it is the feeling of the needs for intern relationship and communication out beyond the schoolwalls. Students may have different needs and vary in their social experiences, including how they choose to think and to decide about their situations, but the result of this survey showed the overall pictures of what they are insisting at the moment for the development of their maturity in living.

Detailed result of the survey indicated as the followings.

1. Learning system:

- $25,3 \%$ said as very difficult,

- $54.4 \%$ said as difficult.

2. Time spent and consumed at school:

- $55,7 \%$ said as very long,

- $31,8 \%$ said as long.

3. Time spent and enjoyed with families and relatives:

- $32,9 \%$ said as very demanding,

- $36,7 \%$ said as demanding.

4. Freedom to decide what they love and what they daily want to do:

- $16,2 \%$ said as no freedom at all,

- $37,5 \%$ said as no freedom.

5. Choices of what they insist:

- $67,5 \%$ requestes to shorten school hours to be back home,

- $36,3 \%$ requested to terminate the class-ranking program. 
The feelings of difficulties in the learning system which consumed almost all daytime draining their brains, sparked a silent revolt against the system; nevertheless, they are helpless and can't do anything. Let's pay the attention to how much they feel as having no independence to decide what they love and what they want to, despite of loving and demanding to have much more enjoyable time with families and relatives.

They are actually looking for mental and peace well-being, and which certainly are not directly related to their higher educational processes and experiences, especially in this transition period. Transition period in life can be particularly challenging; however, many stsudents are likely to be adapting to significant changes in the social lifestyle when they themselves are adjusting to keep studying from time to time in the environments.

It is also important to note that unsuccessful in the adaptation process may likely grow to certain level of stress, although some level of stress does no necessarily have to go to a negative impact.

\section{DISCUSSION}

This sense of golden relationship and communication with frequent positive feelings is expected eventually to prove the strong link of happiness to golden performance, which is among others the school achievement. Though functioning as a developing process, relationship and communication make those students to understand the world, the family and the environments; namely a mental processes and sensory perceptions. Providing an ample time for students to widen their social ife and to learn through social interactions and communications may gain them with more experiences for their happiness and success.

Attaining their well-being is nothing but being happy as a student and as member of grups and environments, which leads them to success in school. Harvard psychologist Daniel Gilbert defines happiness as frequent positive feelings accompanied by an overall sense that one's life has meaning. There is a strong link between happiness in living in an environement and performing well in school. Happier students tend to perform better, earn better grades, and helpful among schoolmates.

Students often reported that the positive feelings of happiness like enjoyment or fun, really supported their performing in classes. One student explained, "In school, I am happy because I feel accepted by lot of friends, which allows me to enjoy fun learning experience." Another student added, "I am always pushed by myself to perform the best when I have a task that I find to be really interesting and fun". Note how they put their stress on the way how they are able to enjoy fun. Yet almost every student admitted that the most happy part of the day is back from achool and when I sit together with my mum and dad. Although voiced in different ways, students of different ages confessed that their relationships; with classmates, with teachers, with the environment, and with the families, are 
fundametal to their happiness. One student shared, "Everywhere I am happy. I think I feel this way because in school I am surrounded by my friends and teachers who are very nice and caring, and at home I am loved by by parents together with neighbours."

As normal human beings, students have their driving to relate with their parents. This is where every parent has to understand that children learn to manage their emotion by observing how their parents express and manage their emotions. Parents play such a very critical role in modelling how their kids should express their emotions and strong feelings. Parents should initiate acitivities that would encourage their children to ever-improving their social skills. Parents should understand that eventhough kids are undoubtly marked by learning, it is not just learning in school; but also learning to relate to people, to the world around, and to their parents. When parents start to understand and realize how huge is their critical role in modelling and building up their kids of how to face in future, the first stage in the requirement of learning life balance begins to flower their way of thinking to seek happiness in the learning life. Learning process at school has to be balanced with the real world of experience to build their intuitive basis, facing the world with with obstacles and problems, struggling for the searching of their mental peace.

\section{CONCLUSION}

Let the learning institutions and teachers return to the mission of bringing up students to be well-educated citizens and leaders in the future, and parents to understand the mission instead of only driving for class ranking. Heading to mental health as the state of well-being of which every student realizes his or her own potential, study intelligently and at the same time, contribute to the family and community; would shine the love. They will do what they love to be. This is the value of their happiness for their well-being as students. Happy students with intelligence and intellectual growth get good grades. Let us be keen to conduct our national education mission instead of studying and working only for class-ranking without any external considerations. Let them understand how each family works, how to familiarize with the environments, and how to know the other side of the world. Don't put any judgement, just show how they are being love, let them properly grow in the environment, and watch how they will conquer the world. Let them enjoy the learning life balance.

\section{REFERENCES}

Abdul Rahim, Muhammad Hamim bin. (2014). Chasing the Elusive Work Life Balance, Singapore. Patrice Publishing House.

Amstrong, Michael. (2012). Amstrong's Handbook of Human Resource Management Practice, 12 Edition. London, UK: Ashford Colour Press.

Barry J.Wadsworth. Piaget's Theeory of Cognitive and Affective Development. 
David R.Shaffer. (2002). Developmental Psychology, 6th Edition. Wadsworth: Thmson Learning.

Doble, Niharika \& M.V. Supriya. (2010). Gender Differences in the Perception of Work Life Balance. Anna University: India.

European Agency to Safety and Health at Work, Family Issues and Work Life Balance, Number 57

Richard A. Magill. (2001). Motor Learning: Concepts and Applications, 6th Edition, McGraw Hill Higher Education.

Robert L.Solso, Otto H.Maclin, and M.Kimberly Maclin. (2008). Cognitive Psychology. Pearson.

Sturges, jane \& David Guest. (2004). Working to Live or Loving to Work, Work Life Balance early in the Career, King College London, UK, Human Resource Management Journal.

Susi S \& Jawaharrani K. (2011). Work Life Balance: The Key Driver of Employees Engagement, Asian Journal of Management Research, Volume 2 Issue 1.

V.Gregory Payne and Larry D.Isaacs. (2005). Human Motor Development: A Lifespan Approach. McGraw Hill Higher Education. 